\title{
AGE-RELATED CHANGES IN THE STEROID-PRODUCING CELLS OF RAT TESTIS
}

\author{
Darina Barbutska $^{1}$, Yveta Koeva', Mariana Bakalska², Nina Atanassova² \\ ${ }^{1}$ Department of Anatomy, Histology and Embryology, Medical University of Plovdiv and \\ ${ }^{2}$ Institute of Experimental Morphology and Anthropology with Museum, \\ Bulgarian Academy of Sciences, Sofia
}

\begin{abstract}
PURPOSE: Leydig cells are the main source of testicular hormones that control spermatogenesis, the male reproductive tract, and male secondary sexual characteristics. It is now well established that testosterone levels are reduced with ageing suggesting that there must be deficit in the steroidogenic capacity of ageing Leydig cells. In this respect, the present work aims at describing some structural and functional alterations in rat Leydig cells upon ageing.

MATERIAL AND METHODS: Light and electron microscopic observations and immunohistochemistry for $3 \beta$-hydroxysteroid dehydrogenase ( $3 \beta$-HSD) were used to identify some structural and functional features of the Leydig cells of ageing rats.

RESULTS: The routine histological analysis revealed that during aging (21 and 24 month- old rats) the Leydig cells undergo atrophic changes in size rather than reduction in their number and as consequence the interstitium of ageing testes appeared expanded. The immunoexpression of $3 \beta-\mathrm{HSD}$ as a marker of LC steroidogenic activity decreased after 18 months of age and the immunostaining considerably reduced in 24-month-old rats when compared to that in 3-month-old control ones. Ultrastructural study of Leydig cells in ageing rat testes revealed the presence of Leydig cells with intact morphology as well as Leydig cells with different degree of degeneration. An age-related progressive increase in the number of Leydig cells nuclei that exhibit apoptotic changes like chromatin fragmentation and compaction into dense masses leading to nuclear shrinkage was found out.
\end{abstract}

CONCLUSION: The results obtained suggest that effects of ageing on steroidogenesis are mainly due to structural and functional alterations in Leydig cells resulting in a decreased testosterone production.

Key words: Leydig cells, $3 \beta$-hydroxysteroid dehydrogenase, ageing, electron microscopy, rats

\section{INTRODUCTION}

Leydig cells (LCs) are the main source of testicular hormones that control spermatogenesis,

Address for correspondence:

Darina Barbutska, MD

Department of Anatomy, Histology and Embryology

Medical University of Plovdiv

15A Vassil Aprilov Str., 4000 Plovdiv, Bulgaria

e-mail:darinas5@abv.bg

Received: June 24, 2013

Accepted: July 21, 2013 the male reproductive tract and male secondary sexual characteristics. It is now well established that testosterone $(\mathrm{T})$ levels are reduced with ageing, but LC number does not change, suggesting that there must be deficit in the steroidogenic capacity of aging LCs. Using old rats treated with ethane dimethanesulphonate (EDS) which destroys LCs, Chen et al. (5) have reported that newly-formed LCs restore high plasma $\mathrm{T}$ level in the old rats, indicating that the hypothalamic-pituitary axis in the old testis environment remain still intact. Indeed, it is unlikely that deficits of the hypothalamic-pituitary axis are 
primarily responsible for age-related changes in steroidogenesis.

According to some authors (13), reduced aging LC ability to produce $\mathrm{T}$ might be caused by events occurring either outside these cells that impinge upon them, or occurring over time within LCs themselves involving accumulation of free oxygen radicals as byproduct of steroidogenesis. Ageing LCs are characterized by reduction of the number of luteinizing hormone (LH) receptor, cyclic adenosine monophosphate (cAMP) production $(3,6)$, steroidogenic acute regulatory (StaR) protein, peripheral benzodiazepine receptor (PBR), cholesterol transport, and conversion of cholesterol to $\mathrm{T}$ by enzymes residing in the mitochondria and smooth endoplasmic reticulum $(7,10,11)$.

The present investigation aims at describing some structural and functional alterations in rat LCs upon aging.

\section{MATERIAL AND METHODS}

Male Lewis rats at different ages (3,18,21 and 24 months) were used. Testicular fragments approximately $4-5 \mathrm{~mm}$ thick were fixed by immersion in Bouin's fluid for 24 hours, embedded in paraffin, and prepared for routine histological analysis (hematoxylin-eosin staining) and immunohistochemistry for visualization of $3 \beta$ -

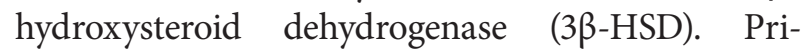
mary rabbit polyclonal antibody against $3 \beta-\mathrm{HSD}$
(1:1000) kindly provided as a gift by Prof. I. Mason (Edinburgh University) was applied. Swine antirabbit biotinylated secondary antibody (E0353, DAKO) (1:500) was applied. Bound antibodies were visualized by incubating the sections with $A B C$ complex/HRP reagent (K0355, DAKO) followed by colour development with $\mathrm{DAB}$ chromogene substrate (K3468, Liquid DAB+ kit, DAKO). For electron microscopy, testicular fragments were fixed in 2,5\% glutaraldehyde, postfixed in $1 \%$ osmium tetraoxide and embedded in Durcopan. Ultrathin sections were observed on EM Opton 109.

\section{RESULTS}

By using light microscopic observation and routine histological analysis, LC atrophy with ageing (18-, 21- and 24 month-old rats) rather than reduction in LC number was established and as consequence, the interstitium of ageing testis appeared enlarged (Fig. $1 \mathrm{~A}, \mathrm{~B})$. Ultrastructural study of LCs in rat testis revealed the presence of LCs with intact morphology as well as LCs with different degree of degeneration. We observed decreased smooth endoplasmic reticulum and mitochondria, fewer and smaller lipid inclusions and residual bodies. The immunoexpression of $3 \beta$-HSD as a marker of LC steroidogenic activity decreased after 18 months of age and the immunostaining considerably reduced in 24-month-old rats when compared to that in 3-month-old control ones (Fig. 2 A, B). During age-
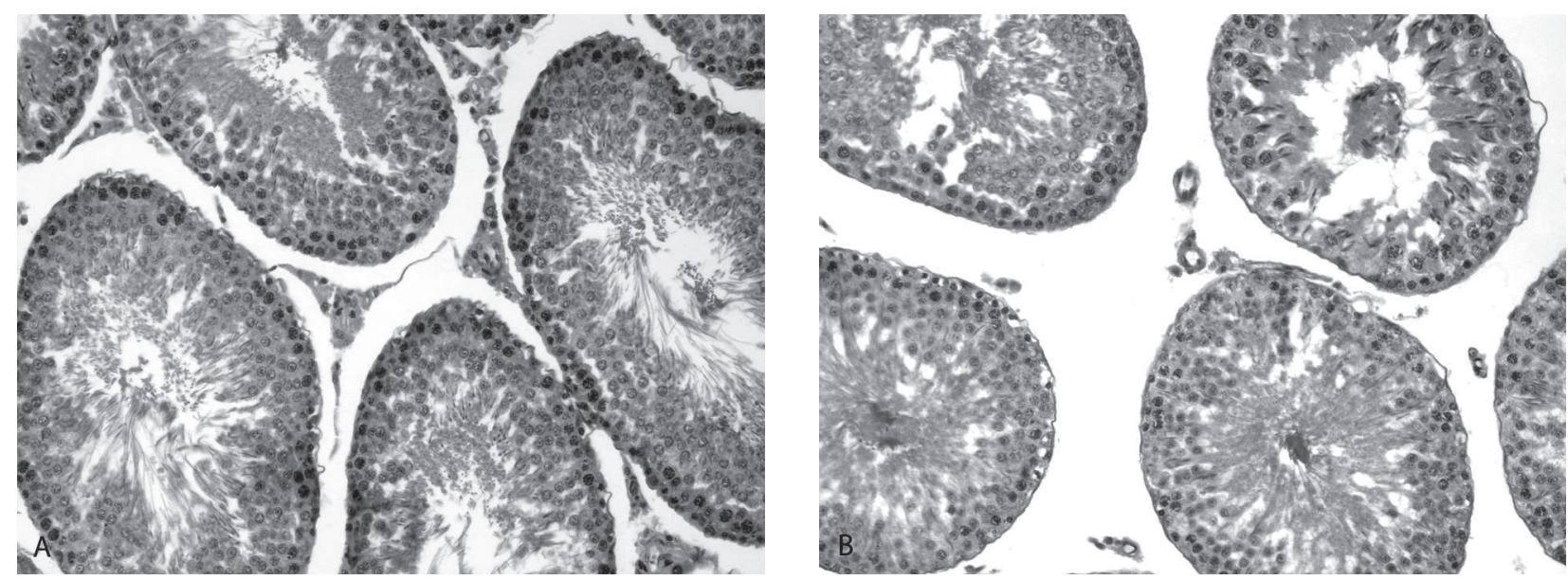

Fig. 1 A, B. Routine histological analysis (hematoxylin-eosin staining). In control testes (A) LCs are arranged in clusters or sheets of cells that surround the tubules and follow the course of blood vessels. Isolated forms in peritubular and perivascular positions are more often seen in 18-and 24-month-old rats, respectively (B). LCs undergo atrophic changes in size and as consequence the interstitium of aging testes appears augmented. Magn. $x 200$ 
Age-related changes in the steroid-producing cells of rat testis

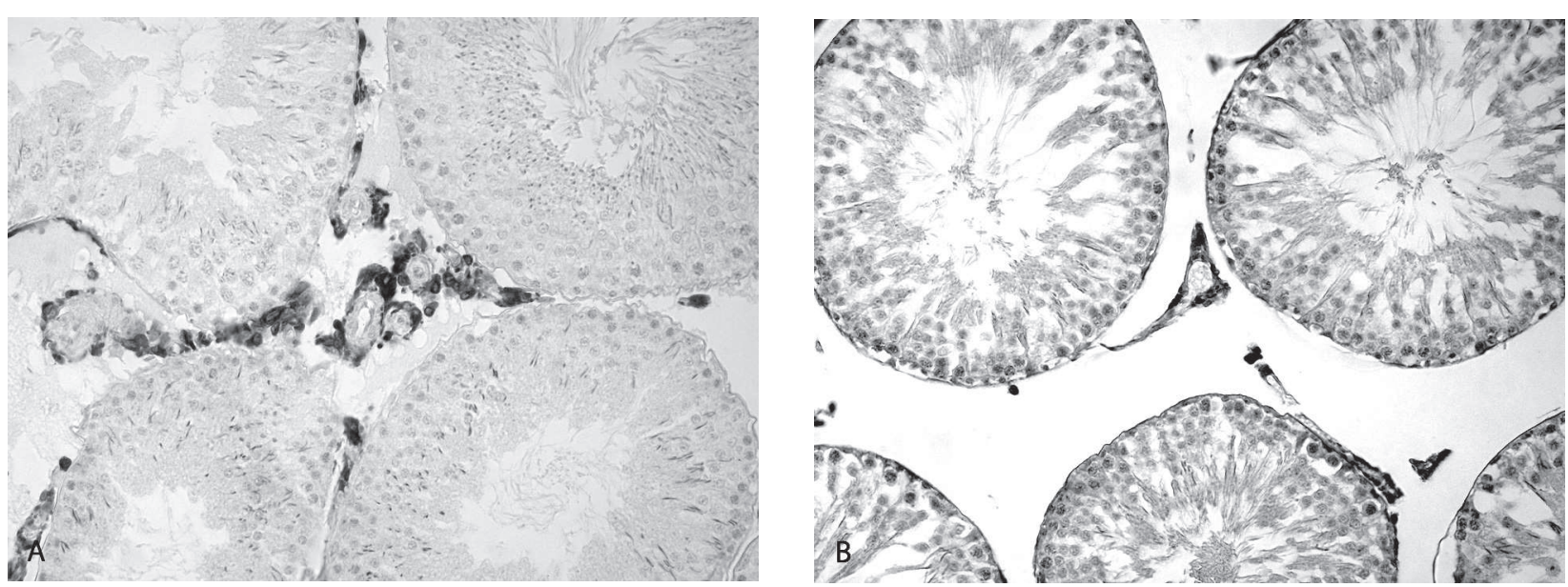

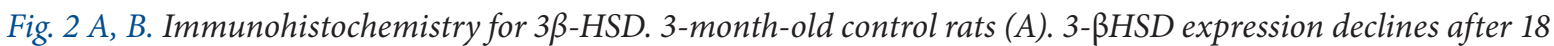
months of age and cytoplasm staining is strongly reduced at 24 months (B). Magn. $x 200$
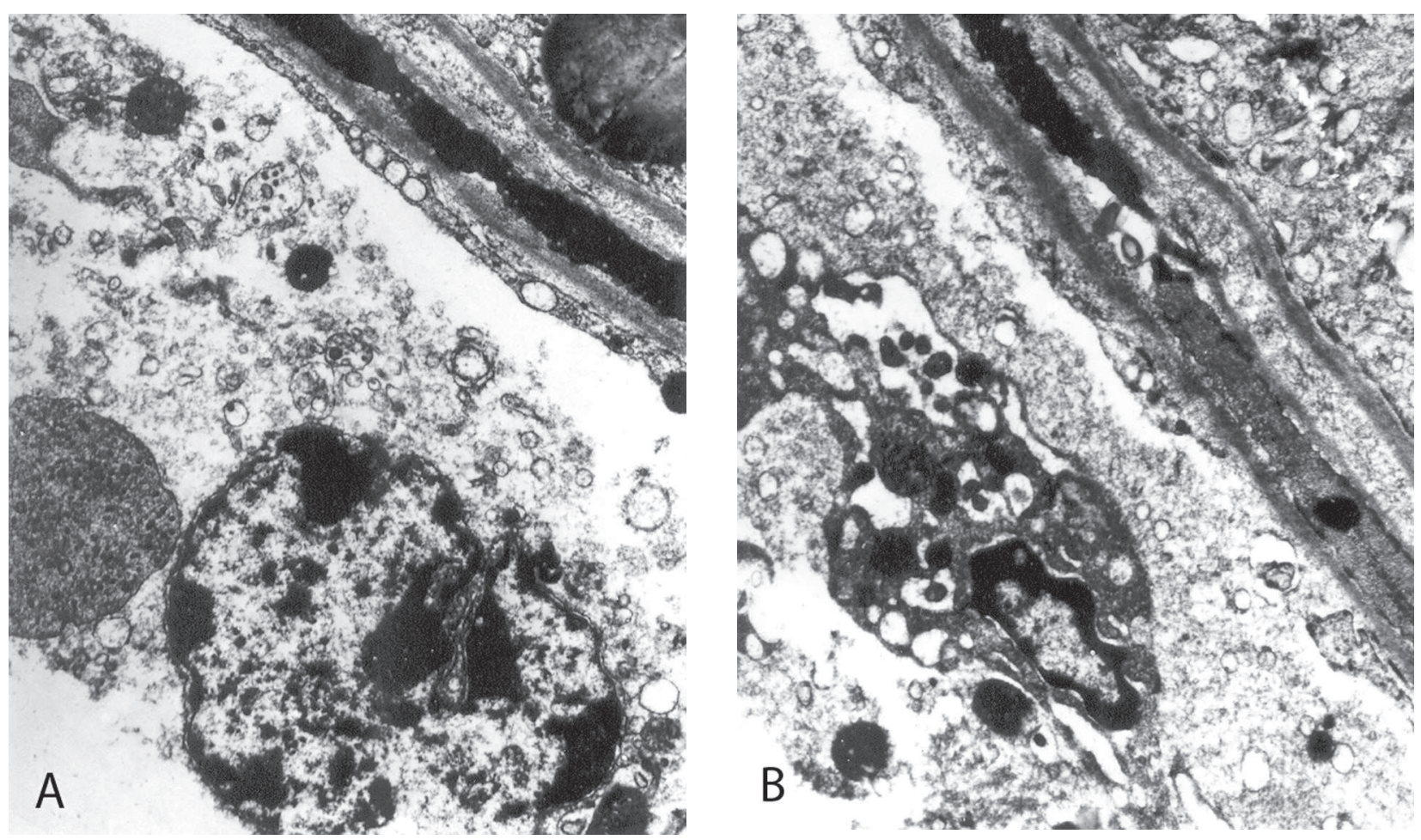

Fig. 3 A, B. Electron microscopic examination. Reduced smooth endoplasmic reticulum and mitochondria along with an accumulated lipid droplets and residual bodies in aging LCs (A). Apoptotic changes in LCs nuclei during aging consist in chromatin fragmentation and compaction into sharply defined dense masses leading to nuclear shrinkage and cellular volume diminution (B). Magn. $x 4500$

ing, apoptotic changes of LC nuclei such as chromatin fragmentation and compaction into dense masses inducing nuclear shrinkage were observed (Fig. 3 A, B).

\section{DISCUSSION}

Our results demonstrate LC atrophy during aging rather than LC number reduction. They are consistent with previous studies in rat testis regarding the effects of ageing on LC structure and 
functional activity. It has been reported that $\mathrm{T}$ levels reduce with ageing while LC number per testis does not change, suggesting that there must be a deficient steroidogenic capacity of individual LCs upon ageing $(4,12)$.

The present findings of reduced $3 \beta-\mathrm{HSD}$ immunoexpression in aged rats are indicative of the suppressed steroidogenic LC activity and strongly correspond with previously published data about decreased serum T levels (3) and age-related reduction of the levels and activities of the key steroidogenic enzymes including $3 \beta$-HSD $(1,9,10)$. The reduced size of LC population observed at light microscopy corresponds to the ultrastructural changes in the nucleus and cytoplasmic organelles. These alterations are indicative of decreased steroidogenic capacity of ageing LCs.

The observed ultrastructural alterations in LCs presenting with marked reduction in the major cytoplasmic organelles such as smooth endoplasmic reticulum and mitochondria could be considered the primary cause for impaired steroidogenesis during ageing. They are in accordance with previously reported data $(2,8)$. Moreover, the progressive alterations in LC nuclei found out in the present study could be a possible sign of their increased apoptotic tendency during ageing.

\section{CONCLUSION}

The present results of ours suggest that agerelated structural and functional alterations in LCs could be considered the primary cause for disturbed steroidogenesis and decreased $\mathrm{T}$ production during ageing.

\section{REFERENCES}

1. Bakalska, M., N. Atanassova, E. Pavlova, Y. Koeva, B. Nikolov. Morphological alterations in rat testis during aging.- Acta Morphol. Anthropol., 13, 2008, 82-86.

2. Chen, H., M. P. Hardy, I. Huhtaniemi, B. R. Zirkin. Age-related decreased Leydig cell testosterone production in the Brown Norway rat.- J. Androl., 15, 1994, No 6, 551-557.

3. Chen, H., I. Huhtaniemi, B. R. Zirkin. Depletion and repopulation of Leydig cells in the testes in aging Brown Norway rats.- Endocrinology, 137, 1996, No 8, 3447-3452.
4. Chen, H., D. Cangello, S. Benson, J. Folmer, H. Zhu, M. A. Trush, et al. Age-related increase in mitochondrial superoxide generation in the testosterone-producing cells of Brown Norway rat testes: relationship to reduced steroidogenic function?- Exp. Gerontol., 36, 2001, No 8, 1361-1373.

5. Chen, H., M. P. Hardy, B. R. Zirkin. Age-related decreases in Leydig cell testosterone production are not restored by exposure to LH in vivo.- Endocrinology, 143, 2002, No 5, 1637-1642.

6. Chen, H., R. A. Irizarry, L. Luo, B. R. Zirkin. Leydig cell gene expression: effects of age and caloric restriction.- Exp. Gerontol., 39, 2004, No 1, 31-43.

7. Culty, M., L. Luo, Z. Yao, H. Chen, V. Papadopoulos, B. Zirkin. Cholesterol transport, peripheral benzodiazepine receptor, and steroidogenesis in aging Leydig cells.- J. Androl.,23, 2002, No 3, 439-447.

8. Ichihara, I., H. Kawamura, L. J. Pelliniemi. Ultrastructure and morphometry of testicular Leydig cells and the interstitial components correlated with testosterone in aging rats.- Cell Tissue Res., 271, 1993, No 2, 241-255.

9. Koeva, Y., M. Bakalska, N. Atanassova, K. Georgieva, M. Davidoff: Age-related changes in the expression of $11 \beta$-hydroxysteroid dehydrogenase type 2 in rat Leydig cells.- Folia Histochem. Cytobiol., 47, 2009, No 2, 281-287.

10. Luo, L., H. Chen, B. R. Zirkin. Leydig cell aging: steroidogenic acute regulatory protein (StAR) and cholesterol side-chain cleavage enzyme.- J. Androl., 22, 2001, No 1, 149-156.

11. Luo, L., H. Chen, B. R. Zirkin. Temporal relationships among testosterone production, steroidogenic acute regulatory protein (StAR), and P450 sidechain cleavage enzyme (P450scc) during Leydig cell aging.- J. Androl., 26, 2005, No 1, 25-31.

12. Wang, C., A. Leung, A. Sinha-Hikim. Reproductive aging in the male Brown Norway rat: a model for the human.- Endocrinology, 133, 1993, No 6, 2773-2781.

13. Zirkin, B. R., H. Chen. Regulation of Leydig cell steroidogenic function during aging. -Biol. Reprod., 63, 2000, No 4, 977-981. 